\title{
Reviews
}

\section{Biologics: a new weapon in the war against autoimmune joint disease}

\author{
Harindu Wijesinghe ${ }^{1}$, Suranjith L Seneviratne ${ }^{2}$, Priyadarshani Galappatthy ${ }^{3}$, Lalith Wijayaratne ${ }^{4}$ \\ Journal of the Ceylon College of Physicians, 2010, 41, 76-82
}

\begin{abstract}
Autoimmune joint diseases occur due to uncontrolled abnormal immune responses (autoimmunity). The commonest autoimmune diseases seen in clinical practice are rheumatoid arthritis, psoriatic arthritis, ankylosing spondylitis and un-differentiated arthritis. These are a source of significant morbidity and some mortality within the population. Non-biologic disease modifying anti-rheumatic drugs (Nonbiologic DMARD's) commonly used in the treatment of these disorders include: methotrexate, sulpha-salazine, leflunomide, hydroxychloroquine and gold. However, a significant proportion of patients do not show adequate responses to these agents. The last few years has seen the introduction of a class of drugs directed at specific patho-physiological abnormalities identified in these diseases. These drugs have not only brought the promise of better response rates but also the possibility of a cure for some patients. These agents are called biologic disease modifying anti-rheumatic drugs (biologic-DMARDS). Biologic-DMARDS show better response rates and appear to be well tolerated by patients. Currently, the biologicDMARDS are mainly used in rheumatoid arthritis, ankylosing spondylitis and psoriatic arthropathy. The currently approved biologics for autoimmune diseases are: TNF alpha antagonists (Infliximab, Etanercept, Adalimumab, and Golimumab), IL-1 antagonists (Anakinra), anti CD-20 antibodies (Rituximab), IL-6 antagonists (Tocilizumab) and the T-cell inhibitor (Abatacept). Recently, increased rates of infection have been reported and the long-term safety profiles of the biologic-DMARDS are still unknown. Due to these problems coupled with
\end{abstract}

${ }^{1}$ Consultant Rhematologist, Rheumatology Unit, Sri Jayewardenepura General Hospital, Sri Lanka.

${ }^{2}$ Consultant Immunologist, Department of Clinical Immunology, St Mary's Hospital and Imperial College, London, UK.

${ }^{3}$ Senior Lecturer, Department of Pharmacology, University of Colombo, Sri Lanka.

${ }^{4}$ Consultant Rheumatologist, Rheumatology Unit, National Hospital of Sri Lanka. the prohibitive costs, the exact place of these agents within treatment algorithms is still been defined. In many developed countries these agents are now included in the management with provision of specific guidance on when and how to use them. Our review outlines important pharmacological and clinical aspects of these agents in the treatment of autoimmune joint diseases.

\section{Introduction}

Autoimmune joint diseases with the exception of rheumatoid arthritis (RA) are rare but collectively affect around $5 \%$ of the population in western countries ${ }^{1}$. These diseases are conventionally managed using nonbiologic disease modifying anti-rheumatic drugs (nonbiologic DMARDS), which include methotrexate, sulphasalazine, hydroxychloroquine and leflunomide in conjunction with corticosteroids and NSAID's. Other immunosuppressants such as azathioprine, cyclophosphamide, cyclosporine and mycophenolate mofetil are used occasionally. These agents have the dual disadvantage of acting non-specifically on the immune cascade as well as affecting other cells (some of which play important roles within the protective immune system). This results in their main side effects, which include infections, liver dysfunction, cytopenias and damage to various other organs. Additionally, treatment with corticosteroids and NSAID's leads to increased morbidity and mortality. Trial data shows that around $50 \%$ of patients fail to achieve disease remission ${ }^{2}$. Because of these factors, there was a pressing need for more effective drugs for effective control of these diseases. Addressing this need, the first biologics appeared in the 1990's. Many randomized controlled trials in RA and other diseases show significantly greater response rates with the biologics when compared to conventional therapies ${ }^{3-5}$.

Compared to traditional drugs these drugs are created by biological processes such as recombinant DNA technologies. They generally exhibit high molecular complexity and are usually monoclonal antibodies or fusion proteins (receptors bound to immunoglobulins). They can be made specifically to counteract or block any given substance in the body or to target any specific cell type. Biologic-DMARD's specifically target selected harmful cells and molecules in the cascade of events involved in autoimmunity. 


\section{Biologics used in autoimmune diseases}

Biologics have had a profound impact on several areas of medicine. In rheumatology, biologics are mainly used in RA, ankylosing spondylitis (AS), and psoriatic arthroapthy (PSA). Of the autoimmune diseases, biologics have mainly been used in RA and most of the trial data are from use in RA. Table 1 illustrates the commonly used biologics in autoimmune joint diseases ${ }^{4}$.

\section{Rheumatoid arthritis: the prototypical auto-} immune disease

In autoimmune disorders, B and/or T cell overactivity continues in the absence of ongoing infections or other discernible causes. This leads to activation of different elements within the immune system, leading to the release a 'slew of immune mediators' that could result in target organ damage. The immune response seen in RA and the sites of action of different biologicDMARDS are shown in Figure 1.

Autoimmunity is triggered by antigens which can be endogenous or exogenous ${ }^{6}$. Antigens bind to toll like receptors (TLR) on dendritic cells and macrophages. These cells then act as antigen presenting cells (APC) to activate T-cells. For a $T$ cell to be activated by an APC, two distinct signals are needed? Cytotoxic T-Lymphocyte Antigen 4 (CTLA-4) is a negative regulator in this process and its action is mimicked by abatacept (an immunoglobulin to CTLA4), one of the biologic-DMARD's. T-cells secrete cytokines, the most important of which are tumor necrosis factor- $\alpha$ (TNF- $\alpha$ ), interleukin-1 and interleukin- 6 . These three cytokines are also the most important cytokines in RA and have been targeted using monoclonal antibodies (Anti-TNF agents, Anakinra and Tocilizumab) as therapy for RA. B-cells are involved in three important roles: antibody production, antigen presentation and cytokine secretion ${ }^{8}$. B-cell depletion using rituximab has proven to be a very effective therapy ${ }^{9}$. B-cell activity also depends on certain cytokines such as BAFF (Bcell activation factor) and APRIL (a proliferation-inducing ligand). Osteoclast activation causes erosions and damage to bones. Osteoclasts need RANKL (Receptor Activator for Nuclear Factor $\kappa \mathrm{B}$ Ligand) interaction with RANK on its surface for its function and survival. Osteoprotegerin (OPG) is the natural inhibitor of this reaction and therapy with $O P G$ may be a future therapeutic direction and is been currently being investigated in the treatment of osteoporosis.

The cells and mediators initially present may change over time; this has important clinical implications in that treatments used initially may not be useful later and vice versa. Although the pathogenic mechanisms between diseases may be broadly similar, important differences could be exploited and prove important in selecting appropriate and targeted treatment options. For example TNF agents will not work in SLE. Even in RA, some persons respond differently to various drugs, and this may be due to the varying immune response that occurs in different individuals.

Table 1. Summary of commonly used biologics mode of action and indications

\begin{tabular}{|c|c|c|}
\hline Biologic & Action & Diseases drug used \\
\hline Infliximab & TNF depletion & $\begin{array}{l}\text { Rheumatoid arthritis (RA), psoriatic arthritis (PSA), } \\
\text { ankylosing spondylitis (AS), Crohns }\end{array}$ \\
\hline Etanercept & TNF depletion & RA, PsA, AS, juvenile idiopathic arthritis (JIA) \\
\hline Adalimumab & TNF depletion & RA, PsA, AS,JIA, Crohns \\
\hline Golimumab & TNF depletion & RA, PsA, AS \\
\hline Rituximab & B-cell depletion & $\begin{array}{l}\text { RA, SLE, Wegeners, dermatomyositis, polymyositis, } \\
\text { immune thrombocytopenic purpura (ITP) }\end{array}$ \\
\hline Abatacept & T-cell deactivation & RA \\
\hline Anakinra & IL-1 antagonist & Adult onset stills disease, periodic fever, JIA \\
\hline Tociluzimab & IL-6 antagonist & RA, JIA, Castlemans and Crohns \\
\hline
\end{tabular}


Figure 1. Immune reaction in RA along with biologic action

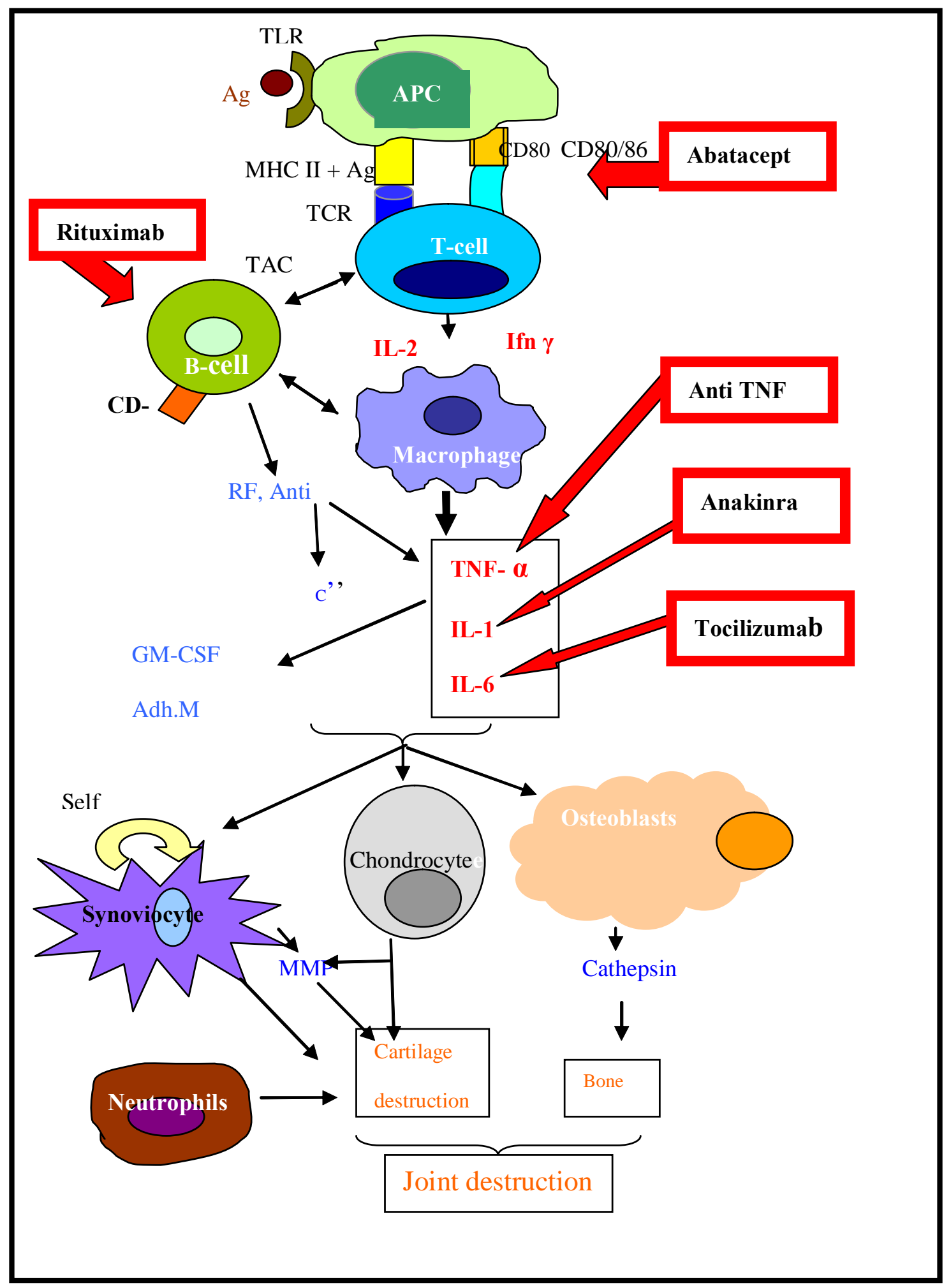

$A P C=$ Antigen presenting cells, $T L R=$ toll like receptors, $T c R=T$-cell receptor, $A g=$ antigen, Ifn=interferon, $M M P=m a t r i x$ metalloproteinases, GM-CSF=granulocyte-monocyte colony-stimulating factor, Adhesion molecules $-\mathrm{AM}$, Chemokines=Chm, BCR=Bcell receptor $\mathrm{TACl}=$ transmembrane activator and calcium-modulator and cytophilinligand interactor BlyS= B-lymphocyte stimulator, $\mathrm{c}^{\prime}=$ complement, RANKL=RANK- ligand, $\mathrm{C}^{\prime}=$ Complement. 


\section{Biologic use in autoimmune joint diseases}

Biologics are mainly used in Rheumatoid arthritis, ankylosing spondylitis and psoriatic arthropathy. As described in Figure 1 they act at various places in the immune system. Contraindications for using all classes of biologics are active infections, congestive heart failure, pregnancy and breast feeding ${ }^{10-12}$. Malignancies appear to be increased in RA, however there appears to be no additional increased risk in RA patients treated with biologics ${ }^{13,14}$. Infusion and injection site reactions are the commonest side effects. There is an increased risk of infections with all biologics. Table 2 gives the various biologics along with their dosing regimens and side effects and contraindications which are not common to all biologics.

\section{Tumor necrosing factor alpha (TNF- $\alpha$ ) inhibition}

The cytokine TNF- $\alpha$ plays a key role in the immune reaction in RA, AS and psoriasis. Four TNF$\alpha$ inhibitors are available for clinical use and these are infliximab, adalimumab, etanercept ${ }^{15}$ and golimumab ${ }^{16}$. infliximab is available in Sri Lanka. Other contraindications are latent (untreated) tuberculosis. Screening for TB must be done according to local recom- mendations. Any patient with features suggestive of TB will need specialist advice regarding anti-TNF treatment. Development of human anti-chimeric antibodies (HACA) to infliximab may decrease its efficacy while increasing the side effect profile ${ }^{10}$. Development of anti-nuclear antibodies (ANA) ${ }^{17}$ and anti-cardioloipin antibodies have been reported and so has the development of systemic lupus erythematosus (SLE), lupus like syndromes, vascultis and interstitial lung diseases ${ }^{18}$. Patients have also developed demyelinating diseases like optic neuritis, transverse myelitis and multiple sclerosis ${ }^{19}$. These patients have reportedly improved after stopping anti-TNF agents and commencing steroids ${ }^{19}$.

In RA, TNF- $\alpha$ inhibitors have been used since the 1998. The National Institute of Clinical Excellence (NICE) guidelines in the UK and American College of Rheumatology guidelines ${ }^{4}$ recommend the use of a TNF- $\alpha$ inhibitor in patients with active RA not responding to at least 2 standard DMARD's including methotrexate. Use of anti TNF agents is also recommended in early RA with severe disease and poor prognostic features ${ }^{4}$. In treatment failures switching to another TNF- $\alpha$ inhibitor or another biologic is recommended ${ }^{20-22}$.

Table 2. Summary of modes of administration, side effects and contraindications of commonly used biologics

\begin{tabular}{|c|c|c|c|c|}
\hline & Mode & $\begin{array}{l}\text { Frequency and } \\
\text { duration }\end{array}$ & Other side effects & Other contraindications \\
\hline Infliximab & $\mathrm{I} . \mathrm{V}$ & $\begin{array}{l}0,2 \text { weeks then } \\
4-6 \text { weekly }\end{array}$ & $\begin{array}{l}\text { Opportunistic infections, } \\
\text { SLE, lupus like syndromes, }\end{array}$ & $\begin{array}{l}\text { Latent TB, } \\
\text { demyelinating disease }\end{array}$ \\
\hline Etanercept & s.c & Twice weekly or weekly & $\begin{array}{l}\text { vascultis and interstitial lung } \\
\text { diseases }\end{array}$ & \\
\hline Adalimumab & S.c & Every 2 weeks & Demyelinating diseases & \\
\hline Golimumab & S.C & Every 4 weeks & & \\
\hline Rituximab & $\mathrm{I} . \mathrm{V}$ & $\begin{array}{l}0,2 \text { weeks then every } \\
6 \text { months }\end{array}$ & $\begin{array}{l}\text { Progressive multifocal } \\
\text { leukoencephalopathy }\end{array}$ & \\
\hline Abatacept & I.V & $\begin{array}{l}0,2 \text { weeks then } \\
4 \text { weekly infusions }\end{array}$ & & latent TB \\
\hline Tociluzimab & $\mathrm{I} . \mathrm{V}$ & Every 4 weeks & $\begin{array}{l}\text { Increased LDL and liver } \\
\text { enzyme levels and } \\
\text { decreased cell counts }\end{array}$ & latent TB \\
\hline Anakinra & S.c & Daily & & \\
\hline
\end{tabular}

I.V = Intravenous, S.c=subcutaneous

The doses and frequency may vary depending on disease treated and response to treatment.

Duration of treatment is still not agreed upon and will depend on response and costs. 
TNF- $\alpha$ inhibitors are used in psoriatic arthropathy, psoriasis ${ }^{23}$, Juvenile idiopathic arthritis and arthropathy associated with Crohn's disease. In ankylosing spondylitis (AS) they are now recommended as second line therapy after NSAIDs ${ }^{24}$.

\section{Interleukin - 1 (IL- 1) antagonism with anakinra}

Anakinra must be given daily in high doses $^{10}$ and data suggests that it was less efficacious than other biologics ${ }^{25}$. Because of this, it is not commonly used in RA. Anakinra appears to be effective in adult onset stills disease, juvenile idiopathic arthritis as well as in periodic fever syndromes. It is being investigated as a treatment for osteoarthritis ${ }^{10}$.

\section{Interleukin - 6 (IL-6) inhibition with tocilizumab}

Tocilizumab is a humanized monoclonal antibody directed against the IL-6 receptor complex. It has proven efficacy in $\mathrm{RA}^{26}$. Skin eruptions, neutropenia, altered liver functions and transient elevation of cholesterol are reported ${ }^{26}$. It is also reported to be effective in JIA, Castlemans disease and Crohns disease ${ }^{27}$.

\section{B cell therapies}

There are several methods for interfering with Bcell function. Rituximab is an anti-CD20 monoclonal antibody that depletes B-cells in their intermediatestages. Rituximab was first licensed for use in nonHodgkin's lymphoma (NHL) and has been used in more than 700,000 patients $^{28}$. The other main area of use for rituximab is in RA. Several randomized controlled clinical trials (RCT) have proven its efficacy in patients not responding to standard DMARD's as well as TNF blockers ${ }^{20-22}$. Currently rituximab is licensed to be used in combination with methotrexate in patients with moderate to severe RA who have not responded to one or more TNF agents ${ }^{4}$. Rituximab is available in Sri Lanka. After 24 weeks the effect reduces in some patients and repeat infusions may be needed.

There is no mention of increased TB risk in Rituximab treated patients in oncology literature ${ }^{29}$. Rare cases of progressive multifocal leukoencephalopathy $(P M L)$ were reported in SLE patients treated with rituximab ${ }^{10}$. Rituximab has also been used in $\mathrm{SLE}^{30}$, dermatomyositis, polymyositis, immune thrombocytopenic purpura (ITP) ${ }^{31}$, Wegeners granulamatosis ${ }^{32}$ and type II mixed cryoglobulinemia ${ }^{33}$.

\section{T cell costimulation inhibition with abatacept}

Abatacept (CTLA4-Ig) is a recombinant fusion protein that inhibits $\mathrm{T}$-cell stimulation by $\mathrm{APC}^{34}$. RA patients not responding to methotrexate and anti-TNF agents have shown clinically significant responses to abatacept ${ }^{35,36}$. Abatacept is recommended in patients with moderate to severe RA having inadequate responses to one or more DMARD's or to anti-TNF therapies ${ }^{10}$.

\section{Biologics used for other indications}

Some biologic agents already registered for use in oncology and other diseases may in future be used for treating autoimmune diseases. The details of these agents are shown in Table 3.

There are many other biological agents under investigation in laboratories worldwide. Some new agents inhibit B-cell activation (e.g Belimumab ${ }^{37}$ and atacicept (immunoglobulin against TACI) ${ }^{38}$. Recently, The Arthritis Advisory Committee of the US Food and Drug Administration recommended an approval for Benlysta (belimumab) for treatment of autoantibodypositive patients with active systemic lupus erythematosus. They thought the medication was effective in relieving lupus disease flares and that it was safe (despite a slight rise in deaths and suicides among those on the drug compared to placebo). The primary end-points were met in the two BLISS ( -52 and -76) trials $^{39}$. Furthermore, several new Anti-TNF agents including certolizumab (CDP-870) $)^{40}$ are in the pipeline. Other agents undergoing trials are denosumab ${ }^{41}$, Anti IL-17, latrunculin $A^{42}$ and drugs targeting the toll like receptors (MD-2, CD-36). Details of these agents are shown in Table 4.

Table 3. Summary of biologics mode used in other diseases

\begin{tabular}{llll}
\hline Drug & Target & Action & Current use \\
\hline Epratuzumab & anti-CD22 & B-cell depletion & Lymphoma \\
Alefacept & CD2 & Memory effector T cells & Psoriasis \\
Efalizumab & CD11A & Inhibiting T-cell activation & Psoriasis \\
Trastuzumab & HER2 receptor & HER2 antagonist & Breast cancer \\
Denileukin diftitox & Interleukin-2 receptor & Inhibition Il-2 activity & Cutaneous T-cell \\
& & & lymphoma (CTCL) \\
\hline
\end{tabular}


Table 4. Summary of biologics currently being investigated

\begin{tabular}{|c|c|c|c|}
\hline Drug & Action & Current status & Future use \\
\hline Atacicept & B-cell & Phase II & SLE, MS \\
\hline Certolizumab & Anti-TNF & $\begin{array}{l}\text { Phase III } \\
\text { (Precise, RAPID) }\end{array}$ & Same as other TNF agents \\
\hline Denosumab & $\begin{array}{l}\text { Osteoclasts } \\
\text { RANKL-RANK interaction }\end{array}$ & - & RA, osteoporosis \\
\hline Anti-IL-17 mAb & $\mathrm{IL}-17$ & Early-phase trials & RA, Crohns \\
\hline Latrunculin A & Synoviocytes & - & RA \\
\hline Ustekinumab & IL 12/23 inhibition & Phase II & Psoriatic arthritis \\
\hline JAK3 Inhibitor & Signaling molecules & Phase 2 & RA \\
\hline
\end{tabular}

Mab=monoclonal antibody, RA=Rheumatoid arthritis, MS=Multiple sclerosis

\section{Conclusion}

The first line of treatment for RA are the nonbiologic DMARD's. In treatment failures, biologicDMARDS (TNF inhibitors, rituximab, abatacept) come into consideration. In the case of biologic-DMARD treatment failures, one could switch to another class of biologics. Although head to head trials comparing biologics are still not available, available data points to all agents been equally efficacious. The role of biologics in early RA (less than 3 months) is not well established.

In the near future, patients with autoimmune disease may receive customized treatment (Biologics and DMARD's) depending on their genetic and immune makeup, thus improving patient outcomes and reducing long term costs. We may also see the development of the ideal biologic which would be cheap, safe, efficacious and administered orally. However, at the present juncture biologics continue to be costly and there are worries regarding infections and several unknowns about their long term safety profile especially in relation to its risk of malignancies. We are practicing medicine in an age of new discoveries and treatments, but each of these come with its own downsides such as increased cost and new adverse events. We should thus strive towards optimizing our clinical management with the first line treatment regimens and reserve these new marvels for the select few who really need them and would show the most benefit.

\section{References}

1. Jacobson DL, Gange SJ, Rose NR, Graham NM. Epidemiology and estimated population burden of selected autoimmune diseases in the United States. Clin Immunol Immunopathol 1997; 84: 223-43.
2. Bakker MF, Jacobs JW, Verstappen SM, Bijlsma JW. Tight control in the treatment of rheumatoid arthritis: efficacy and feasibility. Ann Rheum Dis 2007; 66 Suppl 3: iii56-60.

3. St Clair EW, van der Heijde DM, Smolen JS, et al. Combination of infliximab and methotrexate therapy for early rheumatoid arthritis: a randomized, controlled trial. Arthritis Rheum 2004; 50: $3432-43$.

4. SAAG KG. American College of Rheumatology 2008 Recommendations for the Use of Nonbiologic and Biologic Disease-Modifying Antirheumatic Drugs in Rheumatoid Arthritis. Arthritis \& Rheumatism (Arthritis Care \& Research) 2008; 59: 762-84.

5. Toussirot E, Wendling D. The use of TNF-alpha blocking agents in rheumatoid arthritis: an update. Expert Opin Pharmacother 2007; 8: 2089-107.

6. Uesugi M, Hayashi T, Jasin HE. Covalent cross-linking of immune complexes by oxygen radicals and nitrite. $\mathrm{J}$ Immunol 1998; 161: 1422-7.

7. MacDonald KP, Nishioka Y, Lipsky PE, Thomas R. Functional CD40 ligand is expressed by T cells in rheumatoid arthritis. J Clin Invest 1997; 100: 2404-14.

8. Youinou P, Jamin C, Saraux A. B-cell: a logical target for treatment of rheumatoid arthritis. Clin Exp Rheumatol 2007; 25: 318-28.

9. Emery P. Rituximab in rheumatoid arthritis: a viewpoint by Paul Emery. BioDrugs 2007; 21: 342.

10. Furst DE, Breedveld FC, Kalden JR, et al. Updated consensus statement on biological agents for the treatment of rheumatic diseases, 2007. Ann Rheum Dis 2007; 66 Suppl 3: iii2-22.

11. Braun J, Davis J, Dougados M, Sieper J, van der Linden S, van der Heijde D. First update of the international ASAS consensus statement for the use of anti-TNF agents in patients with ankylosing spondylitis. Ann Rheum Dis 2006; 65: 316-20. 
12. Braun J, Pham T, Sieper J, et al. International ASAS consensus statement for the use of anti-tumour necrosis factor agents in patients with ankylosing spondylitis. Ann Rheum Dis 2003; 62: 817-24.

13. Askling J, Fored CM, Brandt L, et al. Risks of solid cancers in patients with rheumatoid arthritis and after treatment with tumour necrosis factor antagonists. Ann Rheum Dis 2005; 64: $1421-6$

14. Askling J, Fored CM, Baecklund E, et al. Haematopoietic malignancies in rheumatoid arthritis: lymphoma risk and characteristics after exposure to tumour necrosis factor antagonists. Ann Rheum Dis 2005; 64: 1414-20.

15. Firestein GS. Evolving concepts of rheumatoid arthritis. Nature 2003; 423: 356-61.

16. Inman RD, Davis JC, Jr., Heijde D, et al. Efficacy and safety of golimumab in patients with ankylosing spondylitis: results of a randomized, double-blind, placebo-controlled, phase III trial. Arthritis Rheum 2008; 58: 3402-12.

17. Allanore Y, Sellam J, Batteux F, Job Deslandre C, Weill B, Kahan A. Induction of autoantibodies in refractory rheumatoid arthritis treated by infliximab. Clin Exp Rheumatol 2004; 22: 756-8.

18. Ramos-Casals M, Brito-Zeron P, Munoz S, et al. Autoimmune diseases induced by TNF-targeted therapies: analysis of 233 cases. Medicine (Baltimore) 2007; 86: 242-51.

19. Tanno M, Nakamura I, Kobayashi S, Kurihara K, Ito K. Newonset demyelination induced by infliximab therapy in two rheumatoid arthritis patients. Clin Rheumatol 2006; 25: 929-33.

20. Edwards JC, Szczepanski L, Szechinski J, et al. Efficacy of B-cell-targeted therapy with rituximab in patients with rheumatoid arthritis. N Engl J Med 2004; 350: 2572-81.

21. Emery P, Fleischmann R, Filipowicz-Sosnowska A, et al. The efficacy and safety of rituximab in patients with active rheumatoid arthritis despite methotrexate treatment: results of a phase IIB randomized, double-blind, placebo-controlled, dose-ranging trial. Arthritis Rheum 2006; 54: 1390-400.

22. Cohen SB, Emery P, Greenwald MW, et al. Rituximab for rheumatoid arthritis refractory to anti-tumor necrosis factor therapy: Results of a multicenter, randomized, double-blind, placebo-controlled, phase III trial evaluating primary efficacy and safety at twenty-four weeks. Arthritis Rheum 2006; 54: 2793-806.

23. Mease PJ, Gladman DD, Ritchlin CT, et al. Adalimumab for the treatment of patients with moderately to severely active psoriatic arthritis: results of a double-blind, randomized, placebo-controlled trial. Arthritis Rheum 2005; 52: 3279-89.

24. van der Heijde D, Dijkmans B, Geusens P, et al. Efficacy and safety of infliximab in patients with ankylosing spondylitis: results of a randomized, placebo-controlled trial (ASSERT). Arthritis Rheum 2005; 52: 582-91.

25. Gartlehner G, Hansen RA, Jonas BL, Thieda P, Lohr KN. The comparative efficacy and safety of biologics for the treatment of rheumatoid arthritis: a systematic review and metaanalysis. J Rheumatol 2006; 33: 2398-408.
26. Maini RN, Taylor PC, Szechinski J, et al. Double-blind randomized controlled clinical trial of the interleukin- 6 receptor antagonist, tocilizumab, in European patients with rheumatoid arthritis who had an incomplete response to methotrexate. Arthritis Rheum 2006; 54: 2817-29.

27. Nakahara H, Nishimoto N. Anti-interleukin-6 receptor antibody therapy in rheumatic diseases. Endocr Metab Immune Disord Drug Targets 2006; 6: 373-81.

28. Smolen JS, Keystone EC, Emery P, et al. Consensus statement on the use of rituximab in patients with rheumatoid arthritis. Ann Rheum Dis 2007; 66: 143-50.

29. Kimby E. Tolerability and safety of rituximab (MabThera). Cancer Treat Rev 2005; 31: 456-73.

30. Tanaka Y, Yamamoto K, Takeuchi T, et al. A multicenter phase I/II trial of rituximab for refractory systemic lupus erythematosus. Mod Rheumatol 2007; 17: 191-7.

31. Parodi E, Nobili B, Perrotta S, et al. Rituximab (anti-CD20 monoclonal antibody) in children with chronic refractory symptomatic immune thrombocytopenic purpura: efficacy and safety of treatment. Int J Hematol 2006; 84: 48-53.

32. White ES, Lynch JP. Pharmacological therapy for Wegener's granulomatosis. Drugs 2006; 66: 1209-28.

33. Zaja F, De Vita S, Mazzaro C, et al. Efficacy and safety of rituximab in type II mixed cryoglobulinemia. Blood 2003; 101: 3827-34.

34. Ingelfinger JR, Schwartz RS. Immunosuppression - the promise of specificity. N Engl J Med 2005; 353: 836-9.

35. Nogid A, Pham DQ. Role of abatacept in the management of rheumatoid arthritis. Clin Ther 2006; 28: 1764-78.

36. Kremer JM, Genant HK, Moreland LW, et al. Effects of abatacept in patients with methotrexate-resistant active rheumatoid arthritis: a randomized trial. Ann Intern Med 2006; 144: 865-76.

37. Dorner T. Crossroads of $B$ cell activation in autoimmunity: rationale of targeting B cells. J Rheumatol Supp/ 2006; 77 : 3-11.

38. Tak PP, Thurlings RM, Rossier C, et al. Atacicept in patients with rheumatoid arthritis: Results of a multicenter, phase ib, double-blind, placebo-controlled, dose-escalating, singleand repeated-dose study. Arthritis Rheum 2007; 58: 61-72.

39. Belimumab: Anti-BLyS Monoclonal Antibody; Benlysta; BmAb; LymphoStat-B. Drugs R D 2010; 10: 55-65.

40. Barnes T, Moots R. Targeting nanomedicines in the treatment of rheumatoid arthritis: focus on certolizumab pegol. Int J Nanomedicine 2007; 2: 3-7.

41. Akama H. [RANKL inhibition as therapy for joint damage]. Nihon Rinsho Meneki Gakkai Kaishi 2007; 30: 404-7.

42. Vasilopoulos Y, Gkretsi V, Armaka M, Aidinis V, Kollias G. Actin cytoskeleton dynamics linked to synovial fibroblast activation as a novel pathogenic principle in TNF-driven arthritis. Ann Rheum Dis 2007; 66 Suppl 3: iii23-8. 